\title{
Intra-Daily FX Optimal Portfolio Allocation
}

L. Bauwens, W. Ben Omrane and E. Rengifo

Discussion Paper 2006-5

Département des Sciences Économiques

de l'Université catholique de Louvain 


\title{
CORE DISCUSSION PAPER
}

$2006 / 10$

\section{INTRA-DAILY FX OPTIMAL PORTFOLIO ALLOCATION}

\author{
Luc Bauwens $^{1}$, Walid Ben Omrane, ${ }^{2}$ and Erick Rengifo ${ }^{3}$
}

February 16, 2006

\begin{abstract}
We design and implement optimal foreign exchange portfolio allocations. An optimal allocation maximizes the expected return subject to a Value-at-Risk (VaR) constraint. Based on intradaily data, the optimization procedure is carried out at regular time intervals. For the estimation of the conditional variance from which the VaR is computed, we use univariate and multivariate GARCH models. The result for each model is given by the best intradaily investment recommendations in terms of the optimal weights of the currencies in the risky portfolio.
\end{abstract}

Keywords: Optimal portfolio selection; Value-at-Risk; GARCH models; Foreign exchange markets.

JEL Classification: C32, C53, G11.

\footnotetext{
${ }^{1}$ CORE and Department of Economics, Université catholique de Louvain, Voie du Roman Pays 34, B-1348 Louvain-la-Neuve, Belgium. Email: bauwens@core.ucl.ac.be.

${ }^{2}$ Louvain School of Management, Université catholique de Louvain. Email: benomrane@fin.ucl.ac.be.

${ }^{3}$ Corresponding author. Fordham University. New York. USA. Email: rengifomina@fordham.edu.

Work supported in part by the European Community's Human Potential Programme under contract HPRNCT-2002-00232, Microstructure of Financial Markets in Europe. This text presents research results of the Belgian Program on Interuniversity Poles of Attraction initiated by the Belgian State, Prime Minister's Office, Science Policy Programming. The scientific responsibility is assumed by the authors.
} 


\section{Introduction}

In this paper we design and implement a financial model for optimal portfolio allocations of currencies. An optimal allocation maximizes the expected portfolio return subject to a Value-at-Risk (VaR) constraint. In the econometric implementation of the model, we deal with portfolios made of two or three currencies among the euro (EUR), the Great Britain pound (GBP), and the Japanese yen (JPY), the numeraire being the US dollar (USD). Our model is set up for foreign exchange dealers who re-balance their portfolio of currencies at regular time intervals during each trading day and must satisfy a daily VaR constraint.

We use several econometric models to compute the optimal portfolios. Each model is estimated using historical data until some date. Each estimated model then serves to generate, for the next period, an out-of-sample forecast of the expected return and a quantile of the future return distribution, which are used as inputs to compute the optimal allocation of risky currencies. The optimization step also determines the optimal amount of numeraire that investors are allowed to borrow or to lend. The whole procedure is carried out sequentially, by adding one observation at a time to the estimation sample and generating the investment recommendations for the next date.

Our theoretical model is related to the model of Campbell, Huisman, and Koedijk (2001) who propose to allocate financial assets by maximizing the expected return subject to the constraint that the expected maximum loss should meet the VaR constraint. Rengifo and Rombouts (2004) extend this work to a forward looking portfolio selection framework. They implement the model using univariate GARCH models for daily portfolio returns. One disadvantage of using univariate GARCH models is that one needs to re-estimate the model for each change of weights of the risky assets forming the portfolio. This must be done as many times as necessary to solve the optimization problem, i.e. for computing the optimal weights.

As an alternative, if a multivariate GARCH model is used, the multivariate distribution of the returns can directly be used to compute the implied distribution and the VaR of any portfolio, and there is no need to re-estimate the model for different weight vectors. Therefore, we use both univariate and multivariate GARCH and non-GARCH models and compare the performance of the different models on the basis of two economic criteria (the generated wealth and a performance ratio) and two statistical tests (the failure rate and the dynamic quantile tests). Our results indicate clearly that using multivariate GARCH models improves 
the results of the optimal portfolio allocation in terms of the evaluation criteria.

In Section 2, we present the portfolio allocation model. In Section 3, we describe the econometric models we use for the prediction of the VaR. In Section 4, we present an empirical illustration using intradaily data. In the last section, we conclude.

\section{Portfolio Allocation Model}

The portfolio model serves to find the allocation of currencies that maximizes the expected return subject to a VaR constraint. We make the following assumptions:

- Dealers re-balance their currency portfolio regularly (e.g. every thirty minutes) during each trading day. They make capital gains or losses, due to exchange rate fluctuations, and interest gains or losses from their wealth lent or borrowed at the overnight interest rate. However, as the overnight interest rate is very small, we only consider the gains or losses coming from exchange rate fluctuations.

- There is no transaction costs and no bid-ask spreads. This assumption is coherent with the stylized fact found in FX markets, that the effective spread is almost constant and very small, of the order of one basis point.

- There is no failure risk, i.e. the interest rate at which dealers can borrow or lend during the day is the same. In our context, this assumption is acceptable since the difference between the lending and borrowing overnight interest rates is very small.

- The desired amount of USD that dealers may want to borrow can be obtained quickly because of the high speed of intradaily operations. The borrowing can take the form of a "count in advance" that involves no trading costs. If a dealer represents a bank, the borrowing and lending inside the same institution is most of the time granted.

Let $n+1$ be the number of available currencies for trading. Taking the $(n+1)$-th currency as numeraire, in our case the USD, let $p_{i, t}$, with $i=1, \ldots, n$, be the exchange rate between currencies $i$ and $n+1$ expressed in units of currency $n+1$ per unit of currency $i$ (e.g. 1.25 USD per 1 EUR). Define the return of currency $i$ at time $\mathrm{t}+1$ as $r_{i, t+1}=\log \left(p_{i, t+1}\right)-\log \left(p_{i, t}\right)$, for $i=1, \ldots, n$. 
Let $W_{t}$ be the investor's wealth, in USD, at time t. Define $\Omega_{t} \equiv\left\{w_{t} \in R^{n}: \sum_{i=1}^{n} w_{i, t}=1\right\}$ as the set of portfolio weights at time t. Note that this formulation allows for short-selling of some of the currencies in the portfolio and assumes that the income from these short-sellings is invested in the other currencies of the portfolio. Then, $x_{i, t}=w_{i, t} W_{t} / p_{i, t}$ represents the USD value of foreign currency $i$ held at time $t$. This implies:

$$
x_{i, t} p_{i, t}=w_{i, t} W_{t}
$$

and

$$
W_{t}=\sum_{i=1}^{n} x_{i, t} p_{i, t} .
$$

The wealth at time $t+1$ can be expressed as:

$$
W_{t+1}=W_{t}\left(1+\sum_{i=1}^{n} w_{i, t} r_{i, t+1}\right) .
$$

We allow the dealers to borrow or to lend USD according to their degree of risk aversion. If dealers are less risk averse, they would like to borrow in order to invest this money in currencies that allow them to maximize their expected returns. This borrowing can be seen as a leverage to obtain a higher return.

Denote by $b_{t}$ the amount of USD that a dealer can borrow $\left(b_{t}>0\right)$ or lend $\left(b_{t}<0\right)$ at the risk free interest rate $r_{f}$. With borrowing and lending, Equation (3) becomes

$$
W_{t+1}=\left(W_{t}+b_{t}\right)\left(1+\sum_{i=1}^{n} w_{i, t} r_{i, t+1}\right)-b_{t}\left(1+r_{f}\right) .
$$

Dealers wish to maximize their expected wealth since future returns are not known due to the uncertainty present in the markets. Accordingly, Equation (4) in terms of conditional expectations is given by

$$
E_{t} W_{t+1}\left(w_{t}\right)=\left(W_{t}+b_{t}\right)\left(1+E_{t} r_{t+1}\left(w_{t}\right)\right)-b_{t}\left(1+r_{f}\right)
$$

where $E_{t} r_{t+1}\left(w_{t}\right)$ is the expected portfolio return at the end of the rebalancing period. The expectation operator $E_{t}$ is conditional on all the information available at time $t$. In order to maximize this objective function, dealers face two constraints: the budget constraint and the risk constraint given in terms of the VaR. The budget constraint is given by

$$
W_{t}+b_{t}=\sum_{i=1}^{n} x_{i, t} p_{i, t}=x_{t}^{\prime} p_{t}
$$


The VaR constraint for a given intradaily time interval and probability of occurrence $\alpha$ is

$$
P_{t}\left[W_{t+1}\left(w_{t}\right) \leq W_{t}-V a R^{*}\right] \leq \alpha,
$$

where $P_{t}$ is the probability given all the information available at time $t$, and $V a R^{*}$ is the the dealer's desired VaR level.

The intradaily portfolio optimization problem is solved by the maximization of the expected return, Equation (5), subject to the budget constraint, Equation (6), the VaR-constraint, Equation (7), and the simplex constraint $\left(\sum w_{i, t}=1\right)$. The objective is to determine the weights that maximize the expected return subject to those constraints, i.e.

$$
w_{t}^{*} \equiv \arg \max _{w_{t}}\left(W_{t}+b_{t}\right)\left(1+E_{t} r_{t+1}\left(w_{t}\right)\right)-b_{t}\left(1+r_{f}\right)
$$

Substituting the budget constraint (6) in the objective function (5) yields

$$
E_{t} W_{t+1}\left(w_{t}\right)=x_{t}^{\prime} p_{t}\left(E_{t} r_{t+1}\left(w_{t}\right)-r_{f}\right)+W_{t}\left(1+r_{f}\right)
$$

Equation (9) shows that a risk-averse dealer is ready to invest a fraction of his wealth in foreign currencies if the expected return of the portfolio is bigger than the risk free rate.

Substituting (9) (before taking the expectation) in (7) gives

$$
P_{t}\left[x_{t}^{\prime} p_{t}\left(r_{t+1}\left(w_{t}\right)-r_{f}\right)+W_{t}\left(1+r_{f}\right) \leq W_{t}-V a R^{*}\right] \leq \alpha
$$

such that

$$
P_{t}\left[r_{t+1}\left(w_{t}\right) \leq r_{f}-\frac{V a R^{*}+W_{t} r_{f}}{x_{t}^{\prime} p_{t}}\right] \leq \alpha
$$

defines the quantile $q_{t}\left(w_{t}, 1-\alpha\right)$ of the distribution of the portfolio return at the confidence level $\alpha$. Using this result, the investment value can be written as

$$
x_{t}^{\prime} p_{t}=\frac{V a R^{*}+W_{t} r_{f}}{r_{f}-q_{t}\left(w_{t}, \alpha\right)} .
$$

Finally, substituting (12) in (9) and dividing by the initial wealth $W_{t}$ we obtain

$$
\frac{E_{t}\left(W_{t+1}\left(w_{t}\right)\right)}{W_{t}}=\frac{V a R^{*}+W_{t} r_{f}}{W_{t} r_{f}-W_{t} q_{t}\left(w_{t}, \alpha\right)}\left(E_{t} r_{t+1}\left(w_{t}\right)-r_{f}\right)+\left(1+r_{f}\right) .
$$

Thus, the optimal set of weights is given by

$$
w_{t}^{*} \equiv \arg \max _{w_{t}} \frac{E_{t} r_{t+1}\left(w_{t}\right)-r_{f}}{W_{t} r_{f}-W_{t} q_{t}\left(w_{t}, \alpha\right)} .
$$


The well-known two fund separation theorem ${ }^{1}$ applies in this case, i.e. the investor's initial wealth and desired $V a R^{*}$ do not affect the maximization result. Dealers first allocate the currencies and then the amount of borrowing or lending. The latter reflects by how much the VaR of the portfolio, $\left(W_{t} q_{t}\left(w_{t}, \alpha\right)\right)$, differs from the desired $V a R^{*}$ that represents the dealers' degree of risk aversion. The amount of money that a given dealer borrows or lends is obtained by substituting (6) in (12), which gives

$$
b_{t}^{*}=\frac{V a R^{*}+W_{t} q_{t}\left(w_{t}^{*}, \alpha\right)}{r_{f}-q_{t}\left(w_{t}^{*}, \alpha\right)} .
$$

We use this model to compute intradaily portfolio allocations for trading in FX markets. In this context, the time interval during which the optimization is conducted is supposed to be short. This fact introduces some high-frequency data aspects that must be considered in the econometric implementation to estimate the optimal portfolio allocations. An important aspect to consider is the seasonal component present in high frequency data. In the next section we explain in detail the econometric implementation of the model and how we deal with the high-frequency features of the data.

\section{Econometric Implementation}

We want to compute $w_{t}^{*}$ and $b_{t}^{*}$ as defined in Equations (14) and (15), respectively. To implement this, we need to estimate $E_{t} r_{t+1}\left(w_{t}\right)$ and $q_{t}\left(w_{t}^{*}, \alpha\right)$ from historical data (i.e. until date $t-1$ inclusive), using an econometric model of the portfolio return distribution. We can do this sequentially for a sequence of periods and evaluate the ex-post performance of the investments recommended by the econometric procedure.

Our methodology for the estimation of the optimal portfolio allocation and its evaluation comprise five steps that we describe below.

3.1 Adjustment of each currency return for intradaily seasonality

We start by estimating the intradaily component, $\phi_{i}(t)$, which characterizes the second moment of the returns of currency $i$ at time $t$ of the day. Following Andersen and Bollerslev (1997) and Bauwens, Ben Omrane, and Giot (2005), this intradaily seasonal (or diurnal) component is defined as the expected volatility conditioned on time-of-day,

\footnotetext{
${ }^{1}$ See for example Huang and Litzenberger (1988).
} 
where the expectation is computed by averaging the squared observed returns over the cross-sectional time intervals for each day of the week.

In order to get rid of the diurnal pattern of the volatility of intradaily returns, we adjust the returns by dividing them by the square root of $\phi_{i}(t)$ for $i=1, \ldots, n$, to get "deseasonalized" returns. If $r_{i, t}$ is the observed return of currency $i$ at time $t$, and $R_{i, t}$ is the deseasonalized one, then $R_{i, t}=r_{i, t} / \sqrt{\phi_{i}(t)}$. Actually, the function $\phi_{i}(t)$ is different for each day of the week (see Section 4.1).

3.2 Specification and estimation of an econometric model of portfolio returns

For the specification of an econometric model of portfolio returns we distinguish two cases: the univariate and multivariate cases. In the univariate case, we model the deseasonalized portfolio returns $R_{p, t}$ as follows:

$$
R_{p, t}=\mu_{p, t}+\epsilon_{t}
$$

where $\mu_{p, t}$ is the conditional mean and $\epsilon_{t}$ an error term.

In the multivariate setting, we replace $R_{p, t}$ by a $n \times 1$ vector $R_{t}$ which contains the returns $R_{i, t}, i=1, \ldots, n$, of the $n$ foreign currencies at time $t$ :

$$
R_{t}=\mu_{t}+\epsilon_{t}
$$

where $\mu_{t}$ and $\epsilon_{t}$ are $n \times 1$ vectors.

3.2 a). Specification of the conditional mean

We specify the conditional mean of $R_{i, t}$, with $i=p$ in the univariate case, and $i=1, \ldots, n$ in the multivariate case, as the $\operatorname{AR}(1)$ process

$$
\mu_{i, t}=\mu_{i}+\rho_{i} R_{i, t-1}
$$

or as a slowly changing parameter that is estimated by the mean of the observations until time $t-1$ :

$$
\mu_{i, t}=E_{t-1}\left(R_{i, t}\right), \quad \hat{\mu}_{i, t}=\frac{1}{t} \sum_{s=0}^{t-1} R_{i, s} .
$$

$3.2 \mathrm{~b})$. Specification of the conditional variance

In the univariate case, Equation (16), the error term $\epsilon_{t}$ is decomposed as $\sigma_{p, t} z_{t}$ where $z_{t}$ is an IID process with zero mean unit variance. In this case, given a 
portfolio allocation, we compute the deseasonalized portfolio returns to estimate the conditional variance $\sigma_{p, t}^{2}$ using two univariate specifications:

(a) A "non-parametric" model in which we assume that $\sigma_{p, t}^{2}$ is slowly evolving in time and is estimated at time $t$ by the empirical variance of the data until $t-1$.

$$
\sigma_{p, t}^{2}=\operatorname{Var}_{t-1}\left(R_{p, t}\right), \quad \hat{\sigma}_{p, t}^{2}=\frac{1}{t} \sum_{s=0}^{t-1}\left(R_{p, s}-\hat{\mu}_{p, t}\right)^{2} .
$$

(b) The GARCH(1,1) model of Bollerslev (1986), written

$$
\sigma_{p, t}^{2}=\omega_{p}+\delta_{p} \epsilon_{t-1}^{2}+\beta \sigma_{p, t-1}^{2}
$$

In the multivariate case, Equation (17), the error term $\epsilon_{t}$ equals $\Sigma_{t}^{1 / 2} z_{t}$, where $\Sigma_{t}^{1 / 2}$ is, for example, the Cholesky factorization of the $n \times n$ conditional variancecovariance matrix $\Sigma_{t}$, and where the $n \times 1$ vector $z_{t}$ is an IID process with mean zero and variance $I_{n}$ (the identity matrix of order n). For this case we use two multivariate GARCH models (see Bauwens, Laurent, and Rombouts, 2006, for a detailed presentation of multivariate GARCH models):

(c) The dynamic conditional correlation (DCC) model of Tse and Tsui (2002), defined by

$$
\Sigma_{t}=D_{t} \Lambda_{t} D_{t}
$$

The $n \times n$ matrix $D_{t}$ is a diagonal matrix containing the conditional variances $\sigma_{i, t}^{2}$, for $i=1,2, \ldots, n$, each specified as

$$
\sigma_{i, t}^{2}=\omega_{i}+\delta_{i} \epsilon_{i, t-1}^{2}+\beta_{i} \sigma_{i, t-1}^{2},
$$

i.e. a univariate $\operatorname{GARCH}(1,1)$ equation. The $n \times n$ matrix $\Lambda_{t}$ is the conditional correlation matrix, defined by

$$
\Lambda_{t}=\left(1-\theta_{1}-\theta_{2}\right) \Lambda+\theta_{1} \Psi_{t-1}+\theta_{2} \Lambda_{t-1},
$$

where $\Lambda$ is a constant correlation matrix, $\theta_{1}$ and $\theta_{2}$ are non-negative parameters satisfying $\theta_{1}+\theta_{1}<1$, and $\Psi_{t-1}$ is the $n \times n$ correlation matrix of $\epsilon_{\tau}$ for $\tau=t-M, t-M+1, \ldots, t-1$. Its $i, j$-th element is given by

$$
\Psi_{i j, t-1}=\frac{\sum_{m=1}^{M} u_{i, t-m} u_{j, t-m}}{\sqrt{\left(\sum_{m=1}^{M} u_{i, t-m}^{2}\right)\left(\sum_{m=1}^{M} u_{j, t-m}^{2}\right)}},
$$


where $u_{i, t}=\epsilon_{i t} / \sigma_{i, t}$. The scalar $M$ must be greater than or equal to $n$ to ensure that $\Psi_{t}$ is semi-positive-definite. Notice that the right-hand side of (24) is such that the diagonal elements of $\Lambda_{t}$ are equal to one for all $i$ and $t$ (assuming that $\Lambda_{0}$ is a correlation matrix).

(d) The BEKK(1,1,1) model of Engle and Kroner (1995), where the conditional variance-covariance matrix is defined by

$$
\Sigma_{t}=C^{\prime} C+A^{\prime} \epsilon_{t-1} \epsilon_{t-1}^{\prime} A+G^{\prime} \Sigma_{t-1} G,
$$

where $A$ and $G$ are $n \times n$ matrices, and $\mathrm{C}$ is upper triangular.

We assume two parametric distributions for $z_{t}$ : the standard Gaussian distribution and the standard Student- $t$ distribution, each univariate or multivariate depending on whether the model is for $R_{p, t}$ or $R_{t}$. With the Student- $t$ distribution we allow for fat tails in the distribution of $z_{t}$. We have also tried the skewed- $t$ distribution, proposed by Hansen (1994) and extended to the multivariate case by Bauwens and Laurent (2005), in order to allow for asymmetry in the return distribution. It turned out that asymmetry is not needed for the data we used, so that the empirical results in that case are almost identical to those obtained using the (symmetric) Student- $t$ distribution.

Following Mittnik and Paolella (2000), we use the weighted maximum likelihood (WML) procedure in order to give more weight to recent data, i.e.. we multiply

the log-likelihood contributions of the observation of period $t$ by $\rho^{T-t}$, where $\rho$ $(\leq 1)$ is an exponential decay factor and $T$ is the total number of observations used for estimation. If $\rho=1$ we are back to usual ML estimation. We choose $\rho$ as one minus the minimum of the failure rate (defined later in this section) for a given VaR confidence level (see Rengifo and Rombouts (2004) for more details).

\subsection{Estimation of the VaR}

To estimate the VaR we need to go back from the adjusted returns to the original ones. In the univariate case in which we work directly on the portfolio return, we simply multiply the estimated conditional means and standard deviations by the square root of the diurnal component $\phi(t)$ of the portfolio. The Value-at-Risk for time $t$ at the 
Table 1: Summary of models

\begin{tabular}{llcc}
\hline \hline & Model name & $\begin{array}{c}\text { Mean } \\
\text { equation }\end{array}$ & $\begin{array}{c}\text { Variance } \\
\text { equations }\end{array}$ \\
\hline Univariate & Emp-Emp & $(19)$ & $(20)$ \\
& Emp-GARCH & $(19)$ & $(21)$ \\
& AR-GARCH & $(18)$ & $(21)$ \\
\hline Multivariate & & & \\
& Emp-DCC & $(19)$ & $(22)-(25)$ \\
& AR-DCC & $(18)$ & $(22)-(25)$ \\
& Emp-BEKK & $(19)$ & $(26)$ \\
& AR-BEKK & $(18)$ & $(26)$ \\
\hline \hline
\end{tabular}

Numbers in parenthesis denote equation numbers in the paper.

confidence level $\alpha$ is calculated as

$$
V a R_{t, \alpha}^{p}=\left(\hat{\mu}_{p, t}+\hat{\sigma}_{p, t} q_{\alpha}\right) \sqrt{\phi(t)}
$$

where $\hat{\mu}_{p, t}$ and $\hat{\sigma}_{p, t}$ are the forecasted conditional mean and standard deviation, and $q_{\alpha}$ is the $(\alpha)$-th quantile of the distribution of $z_{t}$.

For the multivariate setting, once we have estimated the parameters of the model, we compute the forecast $\hat{\Sigma}_{t}$ of the matrix $\Sigma_{t}$ using one of the multivariate GARCH models. After that, we introduce the diurnal factors by the following transformation:

$$
\bar{\Sigma}_{t}=\operatorname{diag}\left(\sqrt{\phi_{1}(t)}, \ldots, \sqrt{\phi_{n}(t)}\right) \hat{\Sigma}_{t} \operatorname{diag}\left(\sqrt{\phi_{1}(t)}, \ldots, \sqrt{\phi_{n}(t)}\right)^{\prime}
$$

where $\phi_{i}(t)$, for $i=1, \ldots, n$, are the diurnal factors corresponding to each currency. With this matrix we can compute the conditional variance of the portfolio return as

$$
\bar{\sigma}_{t}^{2}=w_{t}^{\prime} \bar{\Sigma}_{t} w_{t}
$$

where $w_{t}$ is $n \times 1$ vector of portfolio weights. We also reintroduce the seasonality factor in each forecasted conditional mean: $\bar{\mu}_{i, t}=\hat{\mu}_{i, t} \sqrt{\phi_{i}(t)}$, for $i=1, \ldots, n$, where $\hat{\mu}_{i, t}$ is defined either as in (19) or, following (18), as $\hat{\mu}_{i}+\hat{\rho}_{i} R_{i, t-1}\left(\hat{\mu}_{i}\right.$ and $\hat{\rho}_{i}$ denoting the WML estimates). Thus, the forecasted conditional mean of the portfolio return is

$$
\bar{\mu}_{t}=w_{t}^{\prime} \hat{\mu}_{t}
$$


Once we have computed $\bar{\mu}_{t}$ and $\bar{\sigma}_{t}^{2}$, the Value-at-Risk for time $t$ at the confidence level $\alpha$ is given by

$$
V a R_{t, \alpha}=\bar{\mu}_{t}+\bar{\sigma}_{t} q_{\alpha}
$$

3.4 Determination of the optimal risky investment and amount to borrow or to lend We compute the portfolio weights that maximize the expected return subject to the VaR constraint according to Equation (14). Once we have determined the optimal weights for the investments in the risky currencies, and given the value of the desired $\operatorname{VaR}\left(\operatorname{Va} R^{*}\right)$, we determine the amount borrowed or lent by using Equation (15).

\subsection{Evaluation of the models}

We use four criteria to evaluate the models: two statistical tests and two economic tests. The first statistical test is the failure rate test proposed by Kupiec (1995). According to this test, the model is correctly specified if the observed portfolio return at time $t$ is bigger than the VaR predicted at $t-1$ for time $t$ in $100 \alpha$ percent of the predictions. The failure rate for the long trading positions is defined as

$$
f=\frac{1}{m} \sum_{t=T-m+1}^{T} \mathbf{1}\left[r_{t}<-V a R_{t, \alpha}\right],
$$

where, $m$ is the number of out-of-sample days, $T$ is the total number of observations, $r_{t}$ is the observed return at time $t, V a R_{t, \alpha}$ is the threshold value and $\mathbf{1}$ denotes the indicator function. Correspondingly, the failure rate for short trading positions is defined as the percentage of positive returns larger than the one-step-ahead VaR for short positions. Let $\eta$ be the number VaR violations in the out-of-sample interval of $m$ points. Then, $\eta$ has a binomial distribution with parameters $\alpha$ and $m$. Ideally, the failure rate should be equal to $\alpha$. Thus, the null hypothesis is $H_{0}: f=\alpha$. The corresponding likelihood ratio statistic,

$$
L R=2 \log \left[f^{\eta}(1-f)^{m-\eta}\right]-2 \log \left[\alpha^{\eta}(1-\alpha)^{m-\eta}\right],
$$

is asymptotically distributed as a $\chi^{2}(1)$ random variable.

A property that the VaR should have, besides respecting the VaR level, is that the VaR violations should not be serially correlated. In order to test this property, we use the dynamic conditional quantile test proposed by Engle and Manganelli (2004). The basic 
idea is that this property can be tested by defining the sequence

$$
h_{t}=\mathbf{1}\left[r_{t}<-V a R_{t, \alpha}\right]-\alpha
$$

such that the expected value of $h_{t}$ is zero. The dynamic quantile test is an (OLS) Fisher test under the null that all regression coefficients, including the intercept, are zero in a regression of the variable $h_{t}$ on its own past, on the current VaR and on any other regressors. We perform the test using the current VaR and five lags of the VaR violations as explanatory variables.

The first economic test we use is based on the comparison of the wealth evolution provided by implementing the recommendations of the different models. Accordingly, the best model is the one that provides the highest wealth (or return) at the end of a forecast period, for a given risk level. The second economic test is based on the comparison of the results through a performance ratio. This performance ratio is defined as the ratio in (14), where the expected return is replaced by the realized return. With this ratio we can compare the results of the different models. The preferred model is the one with the highest performance ratio.

\section{Empirical Illustration}

The foreign exchange market is a market maker based trading system, where dealers interact around the clock (i.e. in successive time zones). The most active trading centers are New York, London, Frankfurt, Sydney, Tokyo and Hong Kong. We consider two portfolio allocation problems: one in which the dealer, located in the US, considers only two currencies (EUR and GBP) and one in which the dealer considers three currencies (EUR, GBP and JPY).

In this section, after describing the data, we present the portfolio recommendations of different econometric implementations, and the results of their statistical and economic evaluations.

\subsection{Data Description}

The database (provided by Olsen and Associates) consists of five-minute quotes for the EUR/USD, GBP/USD, and JPY/USD over the period ranging from January 1st, 1999 until 
December 31st, 2003, i.e. five years. These currency quotes are market makers' quotes and not transaction prices, as should be preferably used. Since Danielsson and Payne (2002) showed that the statistical properties of five-minute US dollar/Deutsche Mark quotes are similar to those of transaction quotes, and transaction quotes are not widely available, we have resorted to using quotes. The database also contains the date, the time-of-day stamped to the five minutes in Greenwich mean time (GMT), and the mid-quotes.

From the five-minute mid-quotes, we compute thirty-minute returns, since we assume that the dealers re-balance their portfolios every thirty minutes. The return at time $t$ is computed as the difference between the logarithms of the mid-quotes at times $t$ and $t-1$. We consider only data for the continuous trading period that goes from 12:00 GMT to 20:00 GMT (8 hours per day). We exclude from the sample all the US holidays and control for the day light-saving-time (the time change between the winter and the summer). Finally, to avoid the trade opening noise, we eliminate the first return of the day. The total number of returns of our sample is equal to 20,144 .

As explained in Section 3, we adjust the returns for the diurnal component of volatility. The seasonally adjusted (SA) returns are obtained by dividing the returns by the square root of their cross-sectional intradaily average volatility. Figure 1 displays the intradaily diurnal functions for each day of the week for the EUR/USD, as an example.

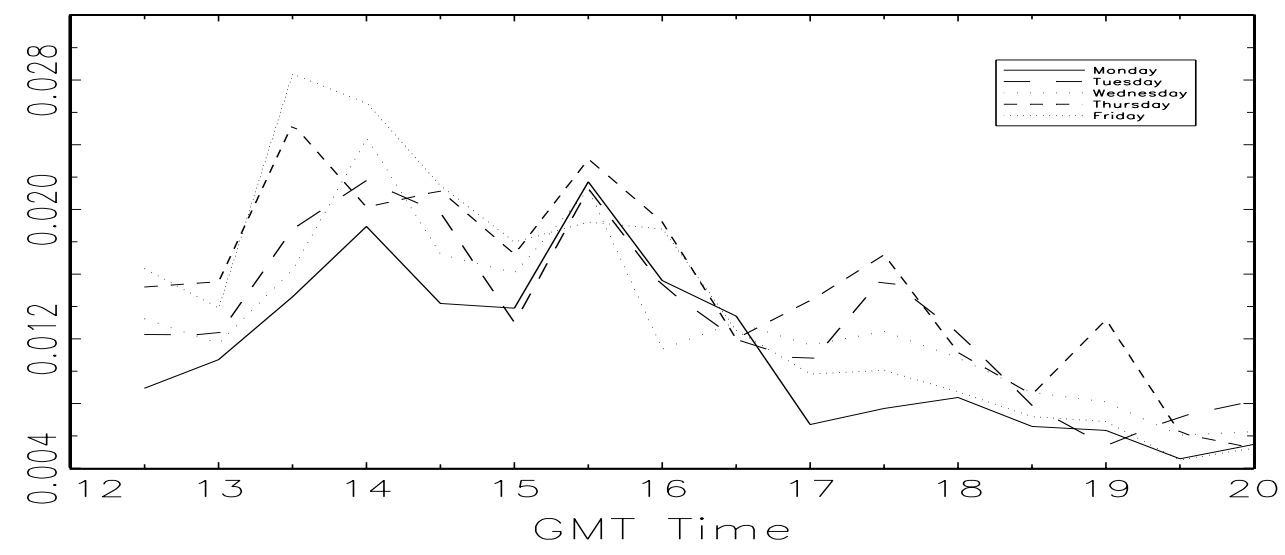

Each curve corresponds to one day of the week.

Figure 1: Diurnal patterns of the EUR/USD volatility

Volatility is generally at its highest level one hour after the US market opening, due to the 
simultaneous activity of the American and the European markets. It decreases around 20h GMT when the New York trading session ends. The profiles of the GBP/USD and USD/JPY diurnal functions are very similar to the ones shown in Figure 1.

Table 2 presents summary statistics of the thirty-minute returns for the three exchange rates, before and after seasonal adjustment. The means of the SA returns are almost equal to zero and their distributions have fatter tails than the normal, but they are almost symmetric. The distributions of the unadjusted returns are more leptokurtic and still close to being symmetric except for the JPY/USD. In the series of SA returns, there is a small but significantly (at the 2.5 percent level) negative autocorrelation of order one and a smaller positive autocorrelation of order two, which is not so much significant. The negative autocorrelation in FX returns has been discussed in the academic literature. According to Goodhart and Figliuli (1991), the negative autocorrelation stems from constraints in the control of positions, while according to Bollerslev and Domowitz (1993) and Lo and MacKinlay (1990), this feature comes from the computation of asynchronous price series at the interval endpoints.

Table 2: Descriptive statistics of thirty-minute returns

\begin{tabular}{l|cc|cc|cc}
\hline \hline & \multicolumn{2}{|c|}{$E U R / U S D$} & \multicolumn{2}{c|}{$G B P / U S D$} & \multicolumn{2}{c}{$J P Y / U S D$} \\
\hline & Returns & SA returns & Returns & SA returns & Returns & SA returns \\
\hline Mean & 0.002 & 0.025 & 0.002 & 0.030 & -0.00005 & 0.002 \\
SD & 0.116 & 0.999 & 0.086 & 0.999 & 0.102 & 1.000 \\
Max & 1.115 & 9.707 & 0.788 & 9.667 & 0.994 & 9.756 \\
Min & -0.845 & -7.403 & -0.562 & -6.696 & -1.343 & -9.363 \\
Skew & 0.038 & 0.067 & 0.086 & 0.087 & -0.345 & -0.168 \\
Kurt & 8.558 & 7.429 & 6.667 & 6.008 & 13.250 & 8.900 \\
$\rho_{1}$ & -0.006 & -0.016 & -0.017 & -0.026 & -0.034 & -0.041 \\
$\rho_{2}$ & 0.013 & 0.008 & 0.009 & 0.006 & 0.005 & 0.003 \\
$Q(1)$ & 0.69 & 5.09 & 5.51 & 13.48 & 23.32 & 34.12 \\
& $(0.105)$ & $(0.024)$ & $(0.019)$ & $(0.0)$ & $(0.0)$ & $(0.0)$ \\
$Q(2)$ & 4.07 & 6.50 & 7.25 & 14.39 & 23.84 & 34.32 \\
& $(0.131)$ & $(0.039)$ & $(0.027)$ & $(0.001)$ & $(0.0)$ & $(0.0)$ \\
\hline \hline
\end{tabular}

The SA returns are the returns adjusted for the diurnal component of volatility (see Section 3.1). SD is the standard deviation, Skew and Kurt are the skewness and kurtosis coefficients, $\rho_{1}$ and $\rho_{2}$ the autocorrelation coefficients of order 1 and $2, Q(1)$ and $Q(2)$ the corresponding Ljung-Box statistics, with their $p$-values below them (between brackets). The number of observations is 20,144 (period from 04/01/1999 until 31/12/2003). 


\subsection{Example of Investment Recommendations}

To illustrate our procedure, we present in detail the investment recommendations of a particular multivariate model. These recommendations specify the amount of US dollars to borrow or to lend and, if applicable, the allocation of this amount to each currency of the risky portfolio. The example is based on a portfolio of three risky currencies (EUR, GBP and JPY). The initial wealth is assumed to be one million USD. For the risk-free interest rate we use the overnight rate in November 2003, equal to $4.47 \%$ (annually). We assume that the dealers re-balance their positions every 30 minutes (16 times per day). At the end of the day, corresponding to the usual practice in FX trading, they close their positions, i.e. they buy (sell) the currencies on which they are short (long), and they lend the remaining USD at the overnight interest rate. However, the effect of this overnight rate has almost no impact on their wealth evolution.

The particular model we consider for this example has a changing conditional mean vector estimated by the sample mean of the observations until time $t-1$. For the the conditional variance-covariance matrix, we use the BEKK specification of Engle and Kroner (1995) coupled with a trivariate Student-t-distribution and we estimate it by WML (setting $\rho$ equal to 0.994, one minus the value that minimizes the failure rate for the specified confidence level). We fix the confidence level $(\alpha)$ for the estimation of the VaR at $10 \%$ and the desired VaR $\left(\mathrm{VaR}^{*}\right)$ at $5 \%$. This means that the VaR level associated with the risky portfolio allocation is smaller than the desired VaR, i.e. this position is less risky than desired. Accordingly, in order to obtain the desired VaR, the investor should borrow a given amount of US dollars and invest it in the risky currencies. We use an estimation sample of 250 days (from 18/11/2002 until 16/11/2003), with 16 observations per day, and then forecast during 30 days out-of-sample (from 17/11/2003 until 31/12/2003).

Figure 2 shows the evolution of the recommended amount of borrowed US dollars as a fraction of the initial wealth. For this specific example, and given that the assumed desired level of risk $\left(\mathrm{VaR}^{*}\right)$ is larger than the the portfolio VaR, the model always suggests to borrow at the risk-free rate and to invest the borrowed money in the risky currency portfolio. The average fraction of the investor's wealth that is borrowed is equal to $61 \%$ over the forecast period, but there is clearly a positive trend in the fraction.

The model recommendations concern also the the percentages of the funds (own and bor- 


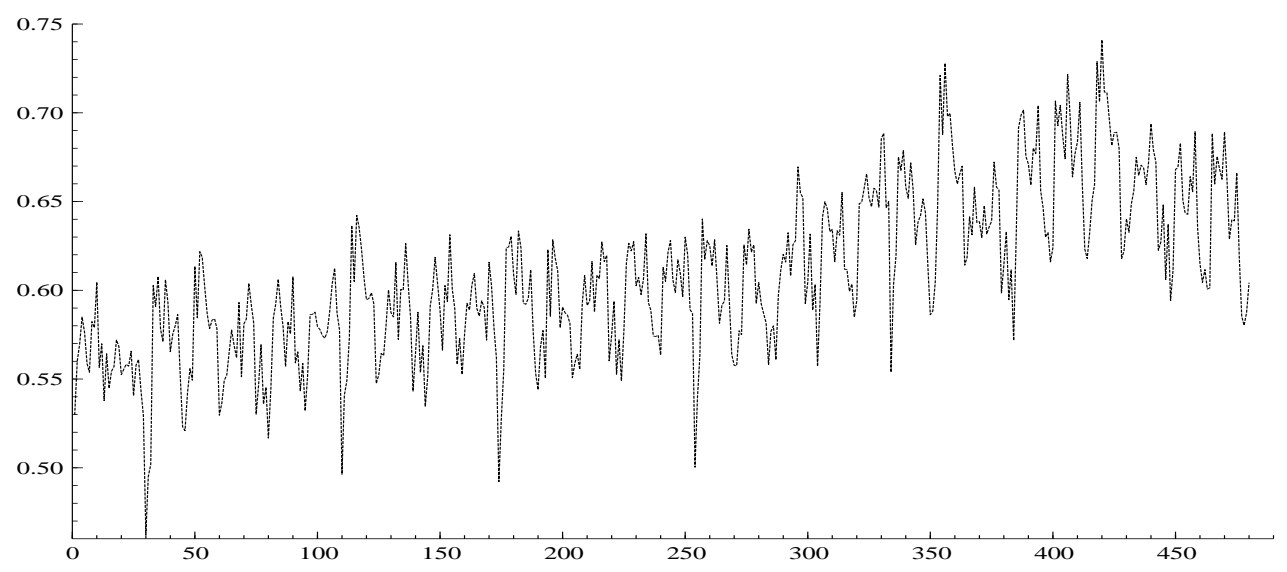

This figure displays the fraction of wealth to be borrowed over 30 trading days of 8 hours, with 30-minutes re-balancing, for the out-of-sample forecast period from 17/11/2003 until 31/12/2003. Portfolios made of three currencies: EUR, GBP and JPY. Model: changing mean and BEKK specification with a Student- $t$ distribution.

\section{Figure 2: Recommended fraction of wealth to borrow}

rowed) to invest in each of the three risky currencies. Figure 3 presents the weight evolution of one of the currencies, the euro. The weights fluctuate in three intervals of values: approximately 0.63-0.68 (most frequently), 0.75-0.80, and 0.45-0.50 (least frequently). On average, the model suggests to invest $67 \%$ of the investor's total funds in EUR. The corresponding averages for GBP and JPY are $58 \%$ and $36 \%$, respectively.

These model recommendations are coherent with the return evolution of the currencies during the out-of-sample period. Table 3 presents the descriptive statistics for this period. The average return of the $E U R / U S D$ is almost $45 \%$ and $160 \%$ larger than for the $G B P / U S D$ and the $J P Y / U S D$, respectively. Therefore, it is not surprising that the investor invests more in EUR and in GBP than in JPY, as recommended by the model.

Finally, Figure 4 presents the wealth evolution of five investment strategies for an initial wealth of one million dollars. Three strategies correspond to investments in a single currency at a time (EUR, GBP, JPY), one corresponds to the optimal portfolio of the three currencies (PORT) derived from the model, and the last one (Rf) consists of investing the initial wealth at the risk-free interest rate. It emerges firstly that the riskless strategy (Rf) generates a smaller final wealth than the other strategies. Secondly, the wealth obtained by the intradaily optimal portfolio allocation model is always larger than the wealth obtained by investing only in GBP or in JPY, and most of the time also larger than the wealth obtained by investing only in EUR. As already pointed out, the results can be explained by the observation that, 


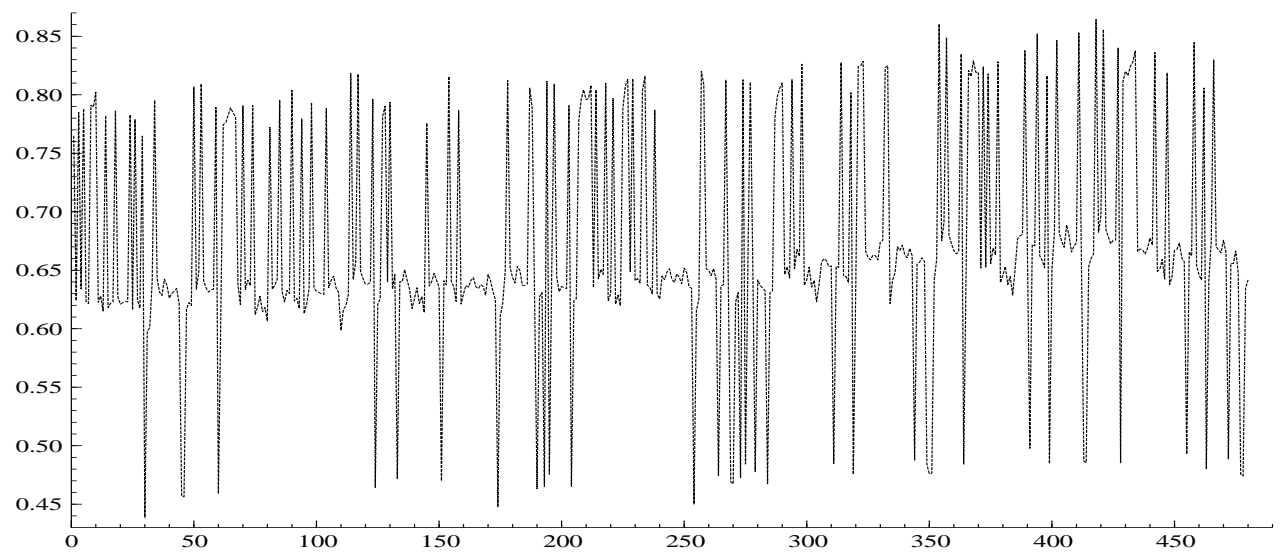

This figure displays the recommended evolution of the euro share over 30 trading days of 8 hours, with 30minutes re-balancing, for the out-of-sample forecast period from 17/11/2003 until 31/12/2003. Portfolios made of three currencies: EUR, GBP and JPY. Model: changing mean and BEKK with a Student- $t$ distribution.

Figure 3: Evolution of the euro weight in the portfolio

Table 3: Descriptive statistics of the forecast period returns (first sample)

\begin{tabular}{l|c|c|c}
\hline \hline & $E U R / U S D$ & $G B P / U S D$ & $J P Y / U S D$ \\
\hline Mean & 0.013 & 0.009 & 0.005 \\
SD & 0.108 & 0.079 & 0.080 \\
Max & 0.704 & 0.524 & 0.311 \\
Min & -0.510 & -0.275 & -0.447 \\
Skew & 0.515 & 0.811 & -0.517 \\
Kurt & 8.005 & 6.989 & 7.002 \\
$\rho_{1}$ & 0.080 & 0.003 & -0.035 \\
$\rho_{2}$ & -0.042 & -0.030 & -0.027 \\
$Q(1)$ & 3.11 & 0.003 & 0.56 \\
& $(0.078)$ & $(0.958)$ & $(0.450)$ \\
$Q(2)$ & 3.95 & 0.39 & 0.98 \\
& $(0.139)$ & $(0.822)$ & $(0.610)$ \\
\hline \hline
\end{tabular}

SD is the standard deviation, Skew and Kurt are the skewness and kurtosis coefficients, $\rho_{1}$ and $\rho_{2}$ the autocorrelation coefficients of order 1 and $2, Q(1)$ and $Q(2)$ the corresponding Ljung-Box statistics, with their $p$-values below them (between brackets). The number of observations is 480 , corresponding to the forecast period from $17 / 11 / 2003$ until 31/12/2003. 


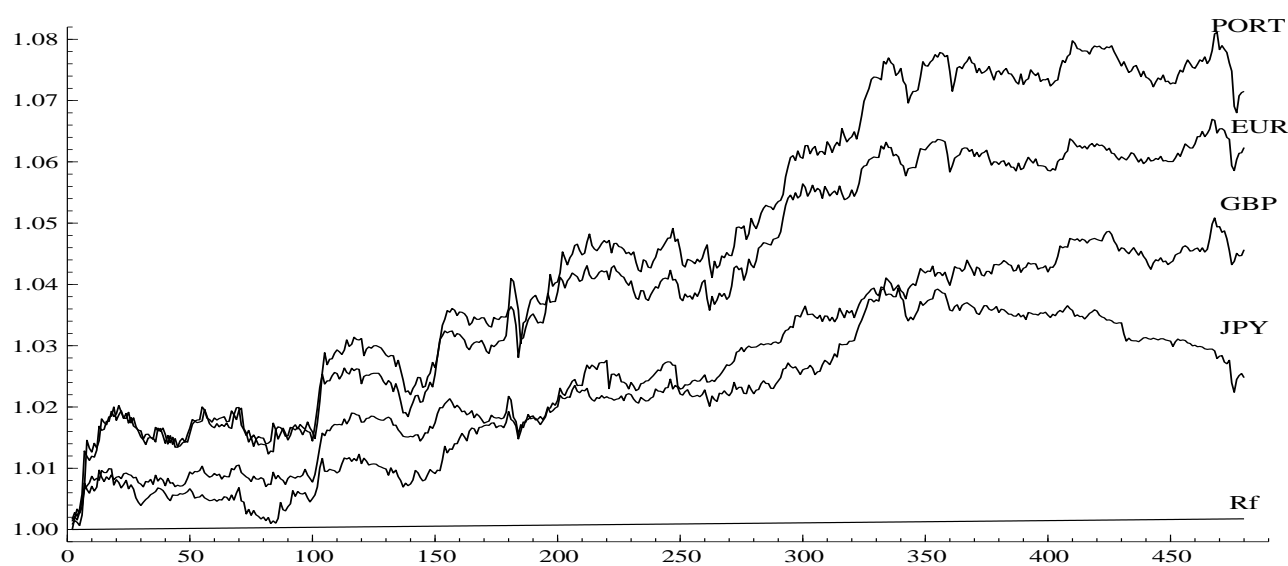

This figure displays the wealth evolution of investing the initial wealth at the risk-free interest rate (Rf), of ingle currency portfolios (EUR, GBP or JPY), and of optimal portfolios (PORT) of the three currencies for the 30-day out-of-sample forecast period from 17/11/2003 until 31/12/2003 (with 8 hours trading per day and 30-minutes re-balancing). Model: changing mean and BEKK specification with a Student- $t$ distribution.

Figure 4: Wealth evolution of five investment strategies

during the forecast period, the returns generated by the euro are most of the time positive.

\subsection{Economic and Statistical Evaluation}

In this part we present the economic and statistical evaluation of the models presented in Section 2. The economic evaluation criteria are the total return $(\mathrm{R})$ and the performance ratio $(\mathrm{PR})$ at the end of the investment period (i.e. an out-of-sample forecast period). The statistical criteria are the failure rate test (FR) and the dynamic quantile test (Dq). These criteria and tests are explained in detail at the end of Section 3.

In Table 4 we present the results for portfolios made of two currencies (EUR and GBP), and in Table 5 the results for portfolios made of three currencies (EUR, JPY, and GBP). The out-of-sample period goes from 17/11/2003 until 31/12/2003 (30 trading days). For the failure rate test, we report the test statistic, and values in bold indicate significance at the $5 \%$ level. For the Dq test, we report the $p$-value of the F-statistic. From these results we draw the following conclusions:

1. Most failure rate tests are significant at the $5 \%$ level for multivariate models, but the reverse is true for univariate models. However, we observe that the models are conservative, since most of the failure rates are below the desired $\alpha$. 
Table 4: Evaluation criteria of models for two currencies (EUR and GBP)

\begin{tabular}{ll|cc|cc|cc}
\hline \hline Models & & \multicolumn{2}{|c|}{$\alpha=1 \%$} & \multicolumn{2}{c|}{$\alpha=5 \%$} & \multicolumn{2}{c}{$\alpha=10 \%$} \\
\hline & & Normal & Student & Normal & Student & Normal & Student \\
& $\mathrm{R}$ & 0.056 & 0.048 & 0.080 & 0.082 & 0.104 & 0.111 \\
& $\mathrm{PR}$ & 13.56 & 10.19 & 27.55 & 29.08 & 46.08 & 55.34 \\
& $\mathrm{FR}$ & 0.023 & 0.020 & 0.081 & 0.085 & 0.117 & 0.135 \\
& $\mathrm{Dq}$ & 0.03 & 0.94 & 0.33 & 0.07 & 0.79 & 0.57 \\
\hline \multirow{5}{*}{ Emp-Emp-GARCH } & $\mathrm{R}$ & 0.062 & 0.048 & 0.089 & 0.081 & 0.117 & 0.109 \\
& $\mathrm{PR}$ & 10.66 & 8.82 & 21.94 & 24.05 & 37.77 & 43.68 \\
& $\mathrm{FR}$ & 0.004 & $\mathbf{0 . 0 1 2}$ & 0.019 & 0.017 & 0.038 & 0.046 \\
& $\mathrm{Dq}$ & 0.54 & 0.62 & 0.03 & 0.06 & 0.42 & 0.07 \\
\hline \multirow{5}{*}{ AR-GARCH } & $\mathrm{R}$ & 0.053 & 0.047 & 0.075 & 0.078 & 0.096 & 0.095 \\
& $\mathrm{PR}$ & 9.40 & 12.12 & 18.68 & 20.47 & 31.19 & 52.29 \\
& $\mathrm{FR}$ & $\mathbf{0 . 0 1 0}$ & $\mathbf{0 . 0 0 8}$ & 0.029 & 0.029 & 0.065 & $\mathbf{0 . 0 8 7}$ \\
& $\mathrm{Dq}$ & 0.99 & 0.93 & 0.71 & 0.04 & 059 & 0.01 \\
\hline & $\mathrm{R}$ & 0.048 & 0.038 & 0.068 & 0.063 & 0.084 & 0.096 \\
& $\mathrm{PR}$ & 4.28 & 2.98 & 8.67 & 8.38 & 13.77 & 15.51 \\
& $\mathrm{FR}$ & $\mathbf{0 . 0 1 7}$ & $\mathbf{0 . 0 1 0}$ & $\mathbf{0 . 0 5 4}$ & $\mathbf{0 . 0 5 6}$ & $\mathbf{0 . 0 9 6}$ & $\mathbf{0 . 1 1 6}$ \\
& $\mathrm{Dq}$ & 0.29 & 0.99 & 0.31 & 0.62 & 0.23 & 0.47 \\
\hline \multirow{5}{*}{ AR-DCC } & $\mathrm{R}$ & 0.038 & 0.032 & 0.054 & 0.066 & 0.066 & 0.091 \\
& $\mathrm{PR}$ & 3.31 & 2.88 & 6.76 & 9.76 & 16.74 & 18.22 \\
& $\mathrm{FR}$ & $\mathbf{0 . 0 1 5}$ & $\mathbf{0 . 0 0 8}$ & $\mathbf{0 . 0 4 8}$ & $\mathbf{0 . 0 4 2}$ & $\mathbf{0 . 0 7 9}$ & $\mathbf{0 . 0 8 1}$ \\
& $\mathrm{Dq}$ & 0.99 & 0.99 & 0.23 & 0.29 & 0.06 & 0.91 \\
\hline \hline \multirow{5}{*}{ ER-BE-BEKK } & $\mathrm{R}$ & 0.045 & 0.044 & 0.063 & 0.072 & 0.081 & 0.099 \\
& $\mathrm{PR}$ & 3.94 & 3.47 & 7.90 & 9.43 & 13.09 & 17.50 \\
& $\mathrm{FR}$ & $\mathbf{0 . 0 1 7}$ & $\mathbf{0 . 0 1 0}$ & $\mathbf{0 . 0 5 0}$ & $\mathbf{0 . 0 5 2}$ & $\mathbf{0 . 0 8 1}$ & $\mathbf{0 . 1 0 4}$ \\
& $\mathrm{Dq}$ & 0.99 & 0.99 & 0.10 & 0.40 & 0.18 & 0.34 \\
\hline & $\mathrm{R}$ & 0.049 & 0.043 & 0.088 & 0.071 & 0.101 & 0.093 \\
& $\mathrm{PR}$ & 4.20 & 3.73 & 10.72 & 10.18 & 15.77 & 18.28 \\
& $\mathrm{FR}$ & $\mathbf{0 . 0 1 5}$ & $\mathbf{0 . 0 1 0}$ & $\mathbf{0 . 0 4 0}$ & 0.031 & 0.060 & 0.069 \\
& $\mathrm{Dq}$ & 0.99 & 0.99 & 0.09 & 0.05 & 0.58 & 0.55 \\
\hline
\end{tabular}

This table presents the statistic and economic criteria for evaluating the models over the outof-sample 30-day forecast period from 17/11/2003 until 31/12/2003. R denotes the total return of the investment over the 30-day period. PR is the performance ratio computed according to Equation (14), where the expected return is replaced by the actual return. FR is the empirical failure rate, with bold numbers indicating significance at the $5 \%$ level. Dq is the $p$-value of the F-statistic for the dynamic quantile test (see Section 3). For a definition of the models, see Table 1. 
Table 5: Evaluation criteria of models for three currencies

\begin{tabular}{|c|c|c|c|c|c|c|c|}
\hline \multicolumn{2}{|l|}{ Models } & \multicolumn{2}{|c|}{$\alpha=1 \%$} & \multicolumn{2}{|c|}{$\alpha=5 \%$} & \multicolumn{2}{|c|}{$\alpha=10 \%$} \\
\hline \multirow{5}{*}{ Emp-Emp } & & Normal & Student & Normal & Student & Normal & Student \\
\hline & $\mathrm{R}$ & 0.032 & 0.028 & 0.045 & 0.045 & 0.058 & 0.061 \\
\hline & PR & 1.66 & 1.26 & 3.38 & 3.56 & 5.62 & 6.73 \\
\hline & FR & 0.027 & 0.023 & 0.094 & 0.106 & 0.113 & 0.144 \\
\hline & $\mathrm{Dq}$ & 0.48 & 0.98 & 0.38 & 0.48 & 0.73 & 0.97 \\
\hline \multirow{4}{*}{ Emp-GARCH } & $\mathrm{R}$ & 0.027 & 0.027 & 0.039 & 0.042 & 0.050 & 0.052 \\
\hline & PR & 3.58 & 2.99 & 4.75 & 5.26 & 7.49 & 9.20 \\
\hline & FR & 0.005 & 0.009 & 0.039 & 0.043 & 0.082 & 0.089 \\
\hline & $\mathrm{Dq}$ & 0.41 & 0.23 & 0.14 & 0.23 & 0.56 & 0.38 \\
\hline \multirow{4}{*}{ AR-GARCH } & $\mathrm{R}$ & 0.020 & 0.016 & 0.040 & 0.039 & 0.047 & 0.049 \\
\hline & PR & 2.26 & 1.65 & 6.57 & 6.61 & 6.44 & 7.87 \\
\hline & FR & 0.003 & 0.012 & 0.039 & 0.041 & 0.091 & 0.094 \\
\hline & $\mathrm{Dq}$ & 0.13 & 0.09 & 0.51 & 0.07 & 0.47 & 0.12 \\
\hline \multirow{4}{*}{ Emp-DCC } & $\mathrm{R}$ & 0.026 & 0.023 & 0.044 & 0.048 & 0.060 & 0.070 \\
\hline & $\mathrm{PR}$ & 15.17 & 11.40 & 30.95 & 31.78 & 50.46 & 58.75 \\
\hline & FR & 0.010 & 0.008 & 0.045 & 0.043 & 0.089 & 0.093 \\
\hline & $\mathrm{Dq}$ & 0.99 & 0.99 & 0.32 & 0.35 & 0.37 & 0.42 \\
\hline \multirow{4}{*}{ AR-DCC } & $\mathrm{R}$ & 0.026 & 0.023 & 0.040 & 0.041 & 0.056 & 0.067 \\
\hline & PR & 14.13 & 13.78 & 26.58 & 27.59 & 51.23 & 63.27 \\
\hline & FR & 0.008 & 0.007 & 0.044 & 0.047 & 0.081 & 0.086 \\
\hline & $\mathrm{Dq}$ & 0.99 & 0.99 & 0.26 & 0.36 & 0.78 & 0.31 \\
\hline \multirow{4}{*}{ Emp-BEKK } & $\mathrm{R}$ & 0.029 & 0.022 & 0.043 & 0.045 & 0.062 & 0.070 \\
\hline & PR & 15.26 & 11.34 & 30.93 & 31.29 & 62.46 & 77.12 \\
\hline & FR & 0.017 & 0.008 & 0.033 & 0.043 & 0.091 & 0.094 \\
\hline & $\mathrm{Dq}$ & 0.99 & 0.99 & 0.73 & 0.67 & 0.25 & 0.09 \\
\hline \multirow{4}{*}{ AR-BEKK } & $\mathrm{R}$ & 0.029 & 0.020 & 0.044 & 0.044 & 0.055 & 0.061 \\
\hline & PR & 14.23 & 12.59 & 32.27 & 38.51 & 59.34 & 73.29 \\
\hline & FR & 0.008 & 0.008 & 0.035 & 0.034 & 0.091 & 0.099 \\
\hline & $\mathrm{Dq}$ & 0.95 & 0.94 & 0.72 & 0.65 & 0.12 & 0.09 \\
\hline
\end{tabular}

This table presents the statistic and economic criteria for evaluating the models over the outof-sample 30-day forecast period from $17 / 11 / 2003$ until $31 / 12 / 2003$. $\mathrm{R}$ denotes the total return of the investment over the 30 -day period. $\mathrm{PR}$ is the performance ratio computed according to Equation (14), where the expected return is replaced by the actual return. FR is the empirical failure rate, with bold numbers indicating significance at the $5 \%$ level. Dq is the $p$-value of the F-statistic for the dynamic quantile test (see Section 3). For a definition of the models, see Table 1. 
2. Almost all the models pass the dynamic quantile test at the $5 \%$ significance level, the exceptions being a few univariate models for two currencies. It appears that most models are correctly specified in the sense that the VaR violations are not serially correlated.

3. Compared to the the Student- $t$ distribution, the normal one produces in all cases a higher return and performance ratio when $\alpha=1 \%$, while the reverse conclusion is true in most cases at $5 \%$ and especially at $10 \%$.

4. The returns obtained by estimating the conditional mean using the empirical mean of the data until time $t-1$ are in a large majority of cases not smaller than the returns obtained by estimating the mean using an autoregressive process. For the performance ratios, no specification of the mean dominates the other. In terms of the statistical tests, the two approaches deliver similar results.

5. The results obtained by the BEKK or the DCC models are very similar but it takes almost 50\% more CPU time to use the BEKK model than the DCC model.

6. The returns and the performance ratios obtained by the 'Emp-Emp' model are almost as good as those obtained by the use of the GARCH models. Nevertheless, the 'EmpEmp' model has higher failure rates, which indicates that it is not as correctly specified and that the risk is higher than the target one.

Bauwens, Laurent, and Rombouts (2006) state that whether "the univariate repeated approach is more adequate than the multivariate one" is an open question. According to our results, using a multivariate GARCH model (either the BEKK or the DCC) provides better results in the statistic and economic sense. Moreover, the multivariate approach is more economical in CPU time than the repeated univariate one: for example, the computing time is reduced by 33 per cent for two currencies and by $50 \%$ for three when using the DCC model, compared to a univariate GARCH model (since the latter has to be estimated many times, when searching for the optimal weights of the portfolio).

In order to ensure that the results presented above are not driven by a sequence of 'abnormal' positive returns for some currency, we compute a second set of portfolio allocations for another sample. The estimation period goes from 19/06/2002 until 17/06/2003 and the out-of-sample forecast period from 18/06/2003 until 31/07/2003 (30 days). Figure 5 shows 


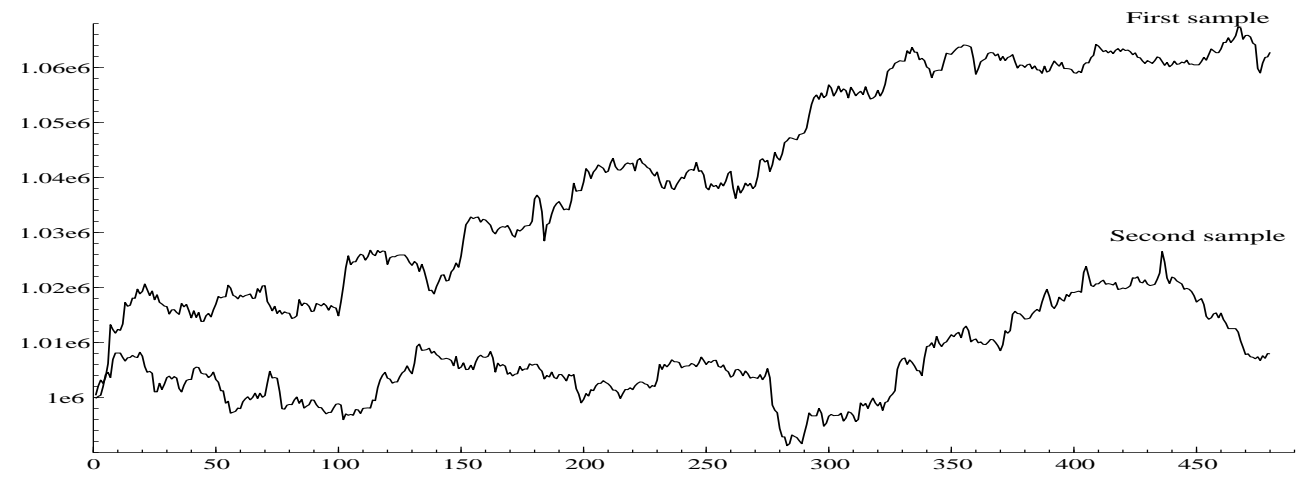

First sample from 17/11/2003 until 31/12/2003, second from 18/06/2003 until 31/07/2003.

Figure 5: Wealth evolution of EUR portfolios for two different samples

the wealth evolution in both samples if everything is invested in EUR. Table 6 presents the descriptive statistics of the second sample.

Comparing the statistics in Tables 6 and 3, we see that the returns for the second 30-day forecast sample are smaller than for the first one, especially for the EUR/USD, while the standard deviations are about the same. Moreover, during the second period, the currency that has the largest mean return is the GBP, and not the EUR. If we look at Tables 7 and 8 , we see that the forecasted returns $(R)$ are considerably smaller than those obtained for the first out-of-sample period (see Tables 4 and 5). These differences are consistent with the smaller returns observed during the second period. However, we draw the same conclusions as from the first forecasting experience: the multivariate GARCH models perform better than the univariate GARCH model; the Student distribution gives better results than the normal when $1-\alpha$ increases; the 'Emp-Emp' model yields returns that are about the same as those provided by the multivariate GARCH models, but it has higher failure rates, and so on. 
Table 6: Descriptive statistics of the forecast period returns (second sample)

\begin{tabular}{l|c|c|c}
\hline \hline & $E U R / U S D$ & $G B P / U S D$ & $J P Y / U S D$ \\
\hline Mean & 0.002 & 0.005 & 0.004 \\
SD & 0.103 & 0.090 & 0.084 \\
Max & 0.391 & 0.314 & 0.316 \\
Min & -0.497 & -0.441 & -0.589 \\
Skew & 0.056 & -0.171 & -0.434 \\
Kurt & 5.654 & 5.076 & 8.916 \\
$\rho_{1}$ & 0.115 & -0.010 & -0.067 \\
$\rho_{2}$ & -0.075 & -0.003 & -0.030 \\
$Q(1)$ & 6.35 & 0.043 & 2.16 \\
& $(0.012)$ & $(0.84)$ & $(0.142)$ \\
$Q(2)$ & 8.14 & 0.046 & 2.47 \\
& $(0.017)$ & $(0.97)$ & $(0.291)$ \\
\hline \hline
\end{tabular}

SD is the standard deviation, Skew and Kurt are the skewness and kurtosis coefficients, $\rho_{1}$ and $\rho_{2}$ the autocorrelation coefficients of order 1 and $2, Q(1)$ and $Q(2)$ the corresponding Ljung-Box statistics, with their $p$-values below them (between brackets). The number of observations is 480 , corresponding to the forecast period from 18/06/2003 until 31/07/2003. 
Table 7: Evaluation of models for two currencies (EUR and GBP), second sample

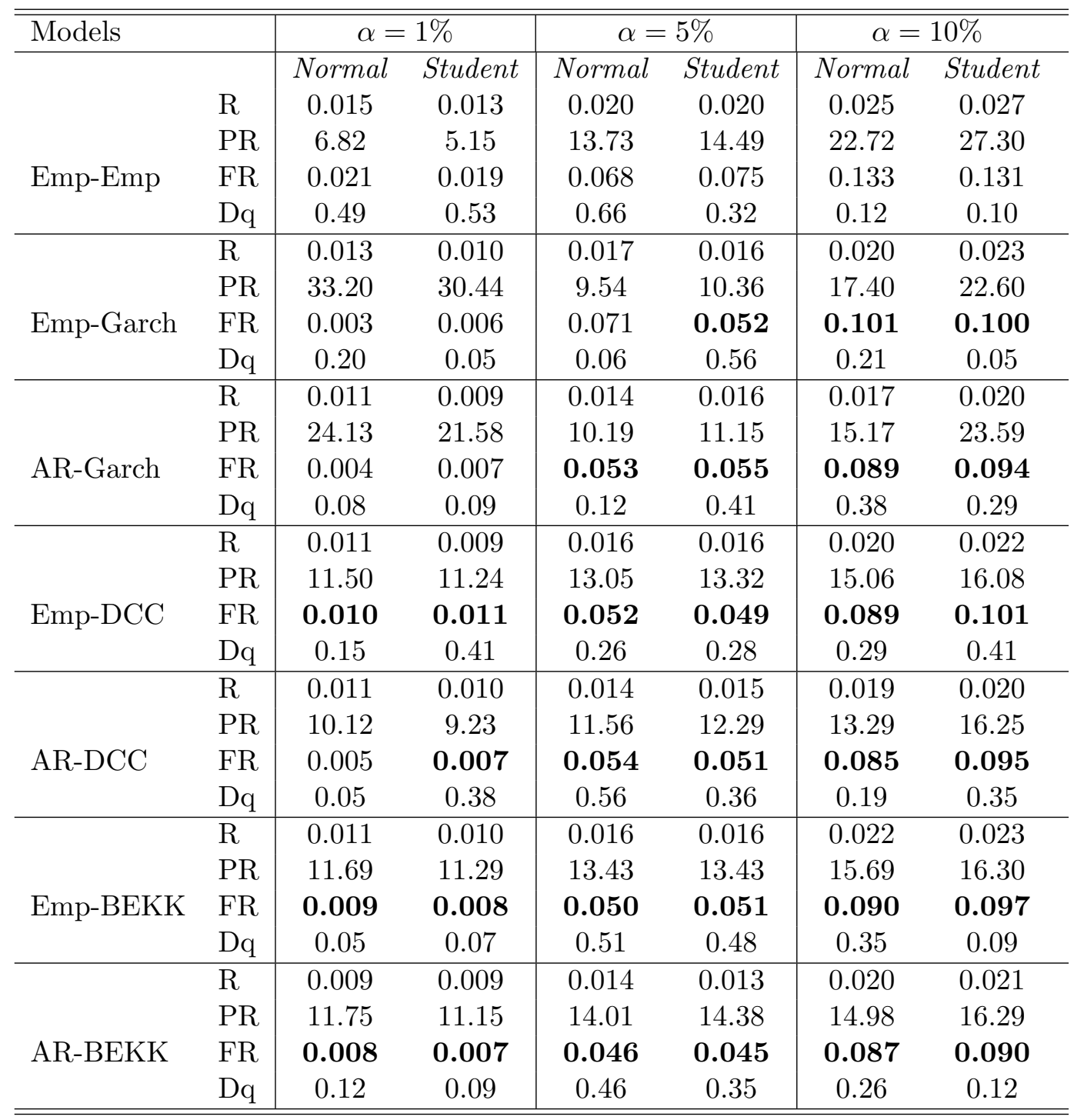

This table presents the statistic and economic criteria for evaluating the models over the outof-sample 30-day forecast period from $18 / 06 / 2003$ to $31 / 07 / 2003$. R denotes the total return of the investment over the 30 -day period. PR is the performance ratio computed according to Equation (14), where the expected return is replaced by the actual return. FR is the empirical failure rate, with bold numbers indicating significance at the $5 \%$ level. Dq is the $p$-value of the F-statistic for the dynamic quantile test (see Section 3). For a definition of the models, see Table 1. 
Table 8: Evaluation criteria of models for three currencies (second sample)

\begin{tabular}{|c|c|c|c|c|c|c|c|}
\hline \multicolumn{2}{|l|}{ Models } & \multicolumn{2}{|c|}{$\alpha=1 \%$} & \multicolumn{2}{|c|}{$\alpha=5 \%$} & \multicolumn{2}{|c|}{$\alpha=10 \%$} \\
\hline \multirow{5}{*}{ Emp-Emp } & & Normal & Student & Normal & Student & Normal & Student \\
\hline & $\mathrm{R}$ & 0.016 & 0.0130 & 0.021 & 0.021 & 0.020 & 0.021 \\
\hline & PR & 10.16 & 7.66 & 20.51 & 21.63 & 23.83 & 28.52 \\
\hline & $\mathrm{FR}$ & 0.038 & 0.029 & 0.075 & 0.079 & 0.126 & 0.133 \\
\hline & $\mathrm{Dq}$ & 0.07 & 0.04 & 0.25 & 0.29 & 0.09 & 0.12 \\
\hline \multirow{4}{*}{ Emp-GARCH } & $\mathrm{R}$ & 0.009 & 0.009 & 0.012 & 0.012 & 0.016 & 0.016 \\
\hline & PR & 58.70 & 43.71 & 15.93 & 19.98 & 21.11 & 28.66 \\
\hline & $\mathrm{FR}$ & 0.006 & 0.003 & 0.049 & 0.050 & 0.095 & 0.096 \\
\hline & $\mathrm{Dq}$ & 0.44 & 0.23 & 0.71 & 0.72 & 0.27 & 0.48 \\
\hline \multirow{5}{*}{ AR-GARCH } & $\mathrm{R}$ & 0.009 & 0.007 & 0.011 & 0.011 & 0.015 & 0.016 \\
\hline & PR & 47.89 & 41.29 & 18.97 & 19.39 & 22.64 & 32.52 \\
\hline & $\mathrm{FR}$ & 0.007 & 0.001 & 0.046 & 0.052 & 0.094 & 0.095 \\
\hline & $\mathrm{Dq}$ & 0.26 & 0.38 & 0.75 & 0.79 & 0.31 & 0.45 \\
\hline & $\mathrm{R}$ & 0.016 & 0.015 & 0.022 & 0.023 & 0.022 & 0.024 \\
\hline \multirow{3}{*}{ Emp-DCC } & PR & 8.48 & 6.75 & 17.11 & 18.28 & 28.52 & 35.19 \\
\hline & FR & 0.016 & 0.010 & 0.048 & 0.054 & 0.094 & 0.094 \\
\hline & $\mathrm{Dq}$ & 0.22 & 0.05 & 0.05 & 0.09 & 0.15 & 0.27 \\
\hline \multirow{4}{*}{ AR-DCC } & $\mathrm{R}$ & 0.015 & 0.015 & 0.019 & 0.018 & 0.020 & 0.021 \\
\hline & $\mathrm{PR}$ & 7.42 & 6.12 & 18.23 & 18.46 & 32.56 & 38.59 \\
\hline & $\mathrm{FR}$ & 0.005 & 0.007 & 0.045 & 0.049 & 0.092 & 0.096 \\
\hline & $\mathrm{Dq}$ & 0.32 & 0.09 & 0.16 & 0.21 & 0.24 & 0.38 \\
\hline \multirow{4}{*}{ Emp-BEKK } & $\mathrm{R}$ & 0.017 & 0.016 & 0.022 & 0.025 & 0.020 & 0.024 \\
\hline & PR & 7.07 & 7.40 & 14.94 & 18.18 & 24.29 & 33.27 \\
\hline & $\mathrm{FR}$ & 0.013 & 0.016 & 0.038 & 0.052 & 0.091 & 0.093 \\
\hline & $\mathrm{Dq}$ & 0.09 & 0.35 & 0.23 & 0.10 & 0.58 & 0.37 \\
\hline \multirow{4}{*}{ AR-BEKK } & $\mathrm{R}$ & 0.015 & 0.014 & 0.020 & 0.019 & 0.018 & 0.020 \\
\hline & PR & 9.05 & 6.97 & 16.19 & 19.15 & 27.85 & 36.34 \\
\hline & FR & 0.014 & 0.016 & 0.035 & 0.041 & 0.087 & 0.090 \\
\hline & $\mathrm{Dq}$ & 0.10 & 0.29 & 0.25 & 0.18 & 0.45 & 0.29 \\
\hline
\end{tabular}

This table presents the statistic and economic criteria for evaluating the models over the outof-sample 30-day forecast period from 18/06/2003 to 31/07/2003. R denotes the total return of the investment over the 30-day period. PR is the performance ratio computed according to Equation (14), where the expected return is replaced by the actual return. FR is the empirical failure rate, with bold numbers indicating significance at the $5 \%$ level. Dq is the $p$-value of the F-statistic for the dynamic quantile test (see Section 3). For a definition of the models, see Table 1. 


\section{Conclusion}

We design a model for maximizing the expected return of a basket of currencies, subject to a VaR constraint. Based on an econometric implementation using intradaily data, we compute the optimal portfolio at regular time intervals during a sequence of trading days. For the estimation of the conditional variance from which the VaR is computed, we use the standard univariate GARCH model of Bollerslev (1986), and two multivariate GARCH models, the BEKK model of Engle and Kroner (1995), and the DCC model of Tse and Tsui (2002). We evaluate the models by two economic criteria and two statistical tests. The procedure we have developed could be a useful tool to help foreign exchange dealers to control the accomplishment of a daily VaR level while maximizing their profits.

Our results show that estimating the VaR from multivariate GARCH models improves the results of the optimal portfolio allocation, compared to using a univariate model. There is no substantial difference between the results obtained by using the BEKK and the DCC models, but the latter is preferable since it takes much less computing time. The Student- $t$ distribution performs better than the normal when the risk level used to define the VaR is large (5 or $10 \%)$, while the reverse holds at $1 \%$.

Future research includes to test other multivariate GARCH models and competitors of this kind of models, such as stochastic volatility models and Wishart autoregressive process proposed by Gourieroux, Jasiak, and Sufana (2004). The latter is a dynamic model for realized volatility matrices. An interesting property of this model is that it is invariant with respect to the choice of the numeraire. Another possible line of study is to work with time-varying re-balancing periods.

\section{References}

Andersen, T. G., and T. Bollerslev (1997): "Intraday Periodicity and Volatility Persistence in Financial Markets," Journal of Empirical Finance, 4, 115-158.

Bauwens, L., W. Ben Omrane, and P. Giot (2005): "News Announcements, Market Activity and Volatility in the Euro/Dollar Foreign Exchange Market," Journal of International Money and Finance, 24, 1108-1125. 
Bauwens, L., and S. Laurent (2005): "A New Class of Multivariate Skew Densities, with Application to GARCH Models," Journal of Business and Economic Statistics, 23, $346-354$.

Baumens, L., S. Laurent, and J. Rombouts (2006): "Multivariate GARCH Models: A Survey," Journal of Applied Econometrics, forthcoming.

Bollerslev, T. (1986): "Generalized Autoregressive Conditional Heteroskedasticity," Journal of Econometrics, 52(4), 5-59.

Bollerslev, T., And I. Domowitz (1993): "Trading patterns and prices in the inter-bank foreign exchange market," The Journal of Finance, 4, 1421-1443.

Campbell, R., R. Huisman, and K. Koedijk (2001): "Optimal Portfolio Selection in a Value-at-Risk Framework," Journal of Banking and Finance, 25, 1789-1804.

Danielsson, J., And R. PAyne (2002): "Real trading patterns and prices in the spot foreign exchange markets," Journal of International Money and Finance, 21, 203-222.

Engle, R., And F. Kroner (1995): "Multivariate Simultaneous Generalized ARCH," Econometric Theory, 11, 122-150.

Engle, R., And S. Manganelli (2004): "CAViaR: Conditional Autoregressive Value at Risk by Regression Quantile," Journal of Business and Economic Statistics, 22, 367-381.

Goodhart, C., And L. Figliuli (1991): "Every minute counts in financial markets," Journal of International Money and Finance, 10, 23-52.

Gourieroux, C., J. Jasiak, and R. Sufana (2004): "The Wishart Autoregressive Process of Multivarite Stochastic Volatility," Mimeo, CREST, CEPREMAP and University of Toronto.

Hansen, B. (1994): "Autoregressive Conditional Density Estimation," International Economic Review, 35, 705-730.

Huang, C., And R. Litzenberger (1988): Foundations for Financial Economics. NorthHolland, Amsterdam. 
KupIEc, P. (1995): "Techniques for Verifying the Accuracy of Risk Measurement Models," The Journal of Derivatives.

Lo, A., And A. MacKinlay (1990): "An econometric analysis of nonsynchronous trading," Journal of Econometrics, 45, 181-211.

Mittnik, S., And M. Paolella (2000): "Conditional Density and Value-at-Risk Prediction of Asian Currency Exchange Rates," Journal of Forecasting, 19, 313-333.

Rengifo, E., and J. Rombouts (2004): "Dynamic Optimal Portfolio Selection in a VaR Framework," Working paper, Center of Operactions Research and Econometrics, Catholic University of Louvain.

Tse, Y., And A. Tsui (2002): "A Multivariate Generalized Auto-regressive Conditional Heteroskedasticity Model with Time Varying Correlations," (20), 351-362, Journal of Business and Economic Statistics. 
Département des Sciences Économiques de l'Université catholique de Louvain

Institut de Recherches Économiques et Sociales

Place Montesquieu, 3

1348 Louvain-la-Neuve, Belgique 